\title{
VIEWPOINTS, MEMÓRIA E CRIAÇÃO: \\ A inserção de teatralidades contemporâneas no espaço escolar.
}

\author{
VIEWPOINTS, MEMORY, CREATION: \\ The insertion of contemporary theatrics at school
}

Adriana Moreira Silva ${ }^{1}$

\section{Resumo}

O texto traça um parâmetro sobre as modificações que a sociedade contemporânea vem sofrendo, e questiona como isso reverbera nas práticas teatrais que são inseridas nas escolas de educação básica. Os viewpoints conceitualizados pela pesquisadora norte - americana Anne Bogart são apontados enquanto uma possibilidade artístico-pedagógica, cuja investigação potencializa a teatralidade já presente nos espaços escolares. Os conceitos sobre memória apresentada por Leal (2011) a partir das ideias de Stanislavski e de Halbwachs, aproximam os alunos de seus próprios contextos e os estimulam a experienciar essa memória pelo uso dos conceitos dos viewpoints. E num processo de afetação, memórias são re-significadas pelas novas experiências e as experiências atuais passam a ser re-elaboradas pelas memórias.

Palavras-chave: teatralidade, memória, escola.

\section{Resumen}

El texto señala a un parámetro sobre los cambios que la sociedad contemporánea está sufriendo, y se pregunta cómo repercute en las prácticas teatrales que se insertan en las escuelas de educación básica. Los puntos de vista conceptualizado por el investigador estadounidense - estadounidense Anne Bogart son nombrados mientras que una posibilidad artística y pedagógica, cuya investigación mejora la teatralidad ya presente en los espacios escolares. Los conceptos de memoria por Leal (2011) a partir de las ideas de Stanislavsky y Halbwachs, cercanos a los estudiantes de sus propios contextos y estimulan experimentar esta memoria mediante el uso de los conceptos de puntos de vista. Y un proceso de asignación, los recuerdos son re-significadas por las nuevas experiencias y las experiencias actuales están siendo re-diseñado por los recuerdos.

Palabras clave: teatralidad, memoria, escuela.

\section{Abstract:}

The text traces a parameter on the changes that contemporary society is suffering, and asks how it reverberates in theater practices that are inserted in the elementary schools. The viewpoints conceptualized by american Anne Bogart are pointed while an artistic and pedagogical possibility, whose research enhances the theatricality already present in school spaces. The concepts of memory by Leal (2011) from the ideas of Stanislavski and Halbwachs, students approach their own contexts and encourage them to experience this memory by using the concepts of viewpoints. And in the allocation process, memories are resignified by new experiences and present experiences come to be re-compiled for the memories.

Keywords: theatricality, memory, scholl.

\footnotetext{
${ }^{1}$ Professora da educação básica e substituta no Curso de Teatro da UFU, Mestre em Artes pela UFU e Atriz do Coletivo Teatro da Margem (Uberlândia/MG).
} 
Os estudos e as investigações acerca das teatralidades contemporâneas se fazem presentes em vários âmbitos das linguagens cênicas. Artistas, estudantes universitários e pesquisadores estão em constante e progressiva busca do diálogo possível entre o teatro e a sociedade em que estamos inseridos hoje.

Torna-se pertinente, portanto, considerar tal processo de modificação e buscar formas de considerá-lo enquanto algo necessário também nas práticas pedagógicas e artísticas que acontecem no espaço escolar. Quando não há dicotomias entre as práticas, o sujeito que se coloca enquanto professor e artista, inserido na escola torna-se capaz de intermediar a aprendizagem por meio do fazer teatral. A partir da investigação de teatralidades que trazem aspectos da contemporaneidade, o espaço escolar é impulsionado a entrar em contato com outras proposições estéticas da cena, permitindo que a relação de ensino/aprendizagem se dê por meio da experiência do fazer teatral.

O professor torna-se capaz de articular suas práticas e discursos teatrais com suas propostas de ensino de teatro. É como se ambas as práticas (artísticas e pedagógicas) estivessem interligadas pela vontade de reformular o teatro, e é somente a partir dessa vontade que a pedagogia é impulsionada, pois ela avança na medida em que os professores se debruçam sobre as novas e infinitas visões acerca do teatro.

Muitas vezes, têm-se a visão de que a escola de ensino básico possui certo isolamento desse processo de modificações que assolam o teatro nos campos das universidades e do teatro profissional. Ao longo dos anos, muito se discutiu em termos de metodologias e as funções da arte inserida no currículo regular de uma escola, mas o que de fato tem sido proposto nos espaços escolares? E como tais práticas reverberam no processo de ensino/aprendizagem dos alunos? Assim, o trabalho no ambiente escolar, muitas vezes, evidencia um quadro cujas perspectivas não abarcavam a gama de possibilidades buscadas e encontradas nas práticas e teorias acerca das linguagens cênicas contemporâneas.

Não deve haver uma dicotomia de proposições artísticas e pedagógicas no teatro, visto que a possibilidade de diálogo entre ambas potencializa a formação de artistas e professores, bem como, não impede a percepção de aspectos que ora transitam pelo pedagógico, ora pelo artístico.

No Brasil, a relação entre pedagogia e o teatro acompanha o processo histórico do país, desde quando o teatro foi usado como forma de catequização. O que está mudando são as formas de se pensar na pedagogia teatral também enquanto fazer artístico dentro da escola. Ainda é comum nas escolas um tipo de entendimento do ensino de teatro que é totalmente de 
ordem festiva e comemorativa. A questão que nos instiga é como possibilitar que os alunos entrem em contato com as inúmeras possibilidades de linguagens, de estéticas e de teatralidades a partir desse contex to que ainda ronda as escolas.

A partir da lei no 9394/96 (LDB - Lei de Diretrizes e Bases -), que legitima o ensino de arte na escola, tem-se o reconhecimento do ensino das artes como área de conhecimento. Porém, os desdobramentos disso são muitas vezes contextuais, ou seja, dependem da maneira como cada escola em particular lida com a presença desses profissionais no seu âmbito. Dependem, portanto, da configuração de cada instituição (pais, alunos, direção) e do modo com que os próprios professores vão construindo suas práticas nas escolas.

André (2007) questiona justamente a regulamentação do ensino por essa lei e pelos PCNs Artes, apontando que o que vem sendo promovido pelas leis é o papel do ensino de artes apenas com intuito de convício social, deixando camufladas as possibilidades de experiências estéticas que favoreçam o aprendizado pelo fazer, pelo apreciar e pela relação que a arte constrói com própria sociedade, seja de maneira transgressora, crítica ou dialogal.

É claro que os princípios de convívio e convivência naturalmente constituem toda e qualquer aula de teatro, mas é fato que a linguagem teatral não está na escola com o intuito exclusivo de valorizar essas questões, que também são inerentes às aulas de matemática, português e etc. Mas o contato com o teatro pode, na verdade, ir na contramão do que de fato as escolas esperam que essa aula seja: nada de alunos sentados; o silêncio pode estar ausente do processo; pode haver reapropriação do espaço (carteiras, mesas, paredes); pode-se trabalhar o entendimento da necessidade de se ultrapassar as regras e pode haver valorização da liberdade de movimento (andar, correr e encostar-se ao outro). Desse quadro, tem-se então, a questão: o que isso causa nas escolas?

Pupo (2001) nos alerta que o que é questionável não é a importância do teatro na formação de indivíduos, pois os questionamentos precisam girar em torno do que dessa relação entre arte e pedagogia têm-se agregado em proposições sobre o teatro em seus tantos contextos. Ainda se alimenta a idéia de que a arte seja feita somente por determinadas pessoas, num caráter de dom, que menospreza totalmente a amplitude do fazer teatral. Estarão as escolas e o ensino de teatro solicitando outras formas de se relacionar com a formação de indivíduos e com ensino/aprendizagem?

Não é de hoje que as pedagogias são reformuladas no contexto educacional, ora na tentativa de sanar determinadas questões, ora questionando antigas práticas. No entanto, é certo que o teatro, ao longo dos anos, vem sendo reformulado por pesquisadores, teatrólogos, 
encenadores, atores, diretores, iluminadores e cenógrafos. Esses, na sua maioria, além dessas funções como artistas, desenvolvem atividades vinculadas ao ensino que poderiam suscitar o engajamento de uma nova pedagogia do teatro.

Em decorrência deste processo, o ensino do teatro também tem seus reflexos com a presença desses outros parâmetros que nos situam inteiramente no contexto atual. A característica do inacabado e do efêmero se reverbera também nas práticas dentro da escola, muitas vezes não pela proposta de professores, mas pela própria forma dos alunos se relacionarem uns com os outros, com o próprio espaço escolar e na forma de dialogarem com os elementos do teatro (formas, gestos, espaço, tempo, movimento, ações, imagens).

Ao contrário do que se pensara até então, a escola não está isolada desse processo de instauração da contemporaneidade. A partir de um olhar mais atento para o universo escolar, é possível perceber que os alunos correspondem a essa contemporaneidade, pois eles possuem características que são muito peculiares a essa época, e que se manifestam cotidianamente dentro do próprio espaço escolar: a utilização constante de tecnologias; o acesso fácil a mídias eletrônicas (computadores, ipodes, tablets e aparelhos celulares); a aptidão para fazerem muitas atividades ao mesmo tempo; a latente vontade de subversão da ordem e a capacidade de argumentação e questionamentos sobre diferentes assuntos e temas.

Soares (2010) aponta que nem sempre o que é feito na sala de aula tem contornos claros, precisos e definidos enquanto estética teatral, mas que essas produções têm singelas expressões que, se impulsionadas e encaminhadas, configuram-se em diálogo com aspectos das teatralidades contemporâneas. Com isso, pode-se constatar que as próprias teatralidades contemporâneas não estão distantes da escola, apenas necessitam de mediação para que possam se sobressair neste contexto que já está previamente modificado pelos indivíduos que ali convivem diariamente.

É exatamente aí que o professor pode se colocar como mediador, pois muitas vezes essa percepção do que está acontecendo na escola vem do olhar atento do professor, que cria, juntamente com os alunos, os momentos propícios para interferir no que está instaurado, de modo a levá-los a reconstruir ou resignificar suas próprias ações dentro do ambiente escolar.

Diversos encenadores como Artaud, Grotowski, Stanislavski, Barba, Brecht, Meyerhold e Brook, cada um há seu tempo, estiveram elaborando visões sobre o fazer teatral não somente artísticas, mas de caráter pedagógico, pois pressupunham a formação contínua de atores na medida em que eles próprios também encontravam outros prismas em relação ao teatro. À medida que esse convívio entre atores e encenadores era intensificado pela 
convivência, os atores absorviam também essa nova visão de teatro e juntamente com ela as possibilidades didáticas para a execução de tal visão.

Atualmente nos ambientes educacionais faltam formações que não passem somente pela pedagogia, mas que sejam transmitidas por meio da experiência diária ${ }^{2}$. A proposta é justamente pela não segregação dos campos de atuação do professor (artístico e/ou pedagógico), mas pela intersecção que pode haver quando não se separa tais campos, porque ambos são impulsores de novas formas de se pensar e de se criar as teatralidades no âmbito da formação.

Apesar disso, Féral (2009) deixa evidente que a formação de professores capazes de repensar a pedagogia está totalmente vinculada ao pensamento que estes constroem enquanto artistas ao longo de sua própria formação, seja em escolas universitárias, escolas livres, ou em grupos de teatro. O que é por ela afirmado é que muitas vezes esses ambientes educacionais não estão preparados para lidarem com novas perspectivas da pedagogia do teatro.

Com as observações de estagiários, evidencia-se um quadro da relação da formação com as práticas artísticas e pedagógicas. Percebe-se que no ensino de teatro nas escolas há uma falta de investimento justamente na formação de professores, que, muitas vezes, parecem desatualizados dos contextos e referências acerca do teatro ${ }^{3}$. Muitos professores não mantêm em suas práticas pedagógicas um vínculo com suas práticas artísticas, ou talvez, elas nem existam, por motivos de origens diversas (mercado de trabalho, situações pessoais, carga excessiva de horas/aula, desinteresse pela prática e etc.).

No entanto, essa falta de vínculo com a prática inevitavelmente, com o passar do tempo, confere-lhes uma formação que traz para a pedagogia do teatro uma visão reducionista e redundante, pois não há outras experiências se aproximando do contexto escolar, ou até mesmo as velhas experiências, que podem, a seu modo, trazer outra perspectiva acerca do teatro na escola.

Propor uma visão acerca de teatralidade contemporâneas na escola ajuda a vislumbrar uma proposta que está aberta para as possibilidades estéticas da contemporaneidade. Mas é imprescindível, entender, ou no mínimo contextualizar, a que estamos denominando de teatralidades contemporâneas.

O contemporâneo retrata a sociedade que hoje, no tempo presente, estrutura-se e organiza-se a partir da descontinuidade, da fragmentação, da rapidez de transmissão das

${ }^{2}$ FÉRAL, Josette. Teatro performativo e pedagogia. Entrevista. Sala Preta, v.1, n.09, p. 255-268, dez.2009.

${ }^{3}$ CABRAL, Beatriz (Biange). O professor-artista: perspectivas teóricas e deslocamentos históricos. Urdimento, vol.01, n 10, p. 35-44. 2008 
informações, dos novos tipos de constituições familiares e de tantas outras formas de relações entre as pessoas. No teatro, tudo isso se reflete pelas infinitas propostas estéticas que emergiram em contraposição ao pensamento estrutural (unidades de tempo, espaço, e ação) do drama. Se os valores, os comportamentos e as relações hoje se dão por outros vieses, naturalmente isso vai se expandindo para os demais campos de atuação dos seres humanos, como o teatro.

Esse teatro contemporâneo também é resultado de esforços de encenadores como Stanislavski, Grotowski, Meyerhold, Artaud e tantos outros que se propuseram a investigar o teatro e suas mil facetas. Hoje é possível ver que as estéticas do teatro contemporâneo são voltadas para uma linguagem que pretende ampliar a concepção do drama, que se manteve vinculada à valorização de personagens, dos diálogos centrados no texto e da ação somente executada no palco tradicional. O teatro contemporâneo está a favor de uma busca de diálogo entre ator e espectador, não pela via da negação, mas pela via da interrogação, do questionamento possível da relação entre teatro e vida.

O termo contemporâneo tão recorrente nas práticas atuais contempla a ideia de teatralidade quando pensamos em uma temporalidade baseada no tempo presente. Essas teatralidades na verdade preencheram as lacunas deixadas pelo contemporâneo, retomando preposições já levantadas por encenadores teatrais ao longo da história e que, agora, ganham a dimensão de "um olhar para o não-vivido no que é vivido" passa a pensar no que ainda pode retornar e no que ainda está para ser transformado.

A própria história da humanidade traz a teatralidade notada e anotada como inerente ao instinto humano, presente no jogo, na mimese corporal e nos papéis sociais que as pessoas assumem ao longo da vida. É como se o corpo humano viesse dotado da capacidade de ser estético, no sentido de querer se fazer entendido e, para isso, cria-se meios de gesticulações, ações, movimentos, formas que exprimem seus pensamentos. Cada pessoa cria para si esses artifícios, que têm dimensões próprias e que criam qualidades de movimentos, especificam tipos de roupas e calçados e usam expressões determinadas para estabelecerem inúmeras relações com o outro. Constitui-se, portanto, a idéia de uma teatralidade que é individual, mas também social e cultural, pois assim como a sociedade convenciona comportamentos e linguagens, a teatralidade torna-se uma convenção das relações, em que médicos, engenheiros e professores ocupam teatralmente seus papeis na sociedade.

${ }^{4}$ AGAMBEN, 2009.p. 19 
Por isso, podemos pensar que a teatralidade não está presente somente no teatro, mas nas diversas cerimônias, encontros, rituais e festas com as quais convivemos cotidianamente. Ela é apropriada até mesmo pelas mídias (rádio, televisão, cinema), na tentativa de tornar algo identificado a suas linguagens, ou ainda, como algo que vai sendo construído juntamente com a cultura de cada povo, como forma de criar suas identidades e características peculiares.

O século XX (a partir das décadas de 1960/70) e os dias atuais vêem dando vazão a essas teatralidades que correspondem à própria estrutura fragmentária, midiática e polissêmica da cena. Os momentos em que se cria a partir do hibridismo ressaltado pelas sociedades contemporâneas encontram-se na relação do aqui/agora. Em tais sociedades, as práticas se dão pelas performances, pelo teatro pós-dramático, pelo teatro performativo, dentre outros que elaboram linguagens que conferem ao espectador teatralidades menos literais e mais concentradas na capacidade do espectador de ler a cena a partir de suas próprias sensações e percepções, não deixando somente para o atuante a função de criar a teatralidade.

Partindo, portanto, da oposição que a literariedade estabelece em relação à teatralidade e as características que isso confere ao teatro dos dias atuais, apontamos três aspectos para abarcar a idéia de teatralidades contemporâneas ${ }^{5}$ :

- A teatralidade é construída a partir do observador, no caso, o espectador;

- A teatralidade não é pensada como algo definido e acabado: ela se estabelece na medida em que os atuantes se colocam em relação à efemeridade do aqui/agora;

- A teatralidade se dá no jogo de relação que o atuante estabelece entre ele e a platéia, a partir de um estado de presença que se manterá pelas diferentes relações com o corpo, o espaço, o tempo e com o espectador.

Pode nos parecer evidente pensar que no caso do teatro e das maiorias das artes é essencial a presença do espectador. Pois bem: assim o é. O teatro é uma atividade que requer necessariamente o olhar do outro sobre si para que o fenômeno teatral possa de fato se estabelecer. O olhar do outro altera, cria, recria e dá sentido à obra, muitas vezes não o sentido literal, lógico e racional, mas aquele que é criado a partir de sua visão, de seus sentidos e de sua percepção. Portanto, pensar em teatralidade é necessariamente pensar que o teatro está sendo feito para o outro, em função também do que o outro estará disposto a enxergar e construir.

${ }^{5}$ CORNARGO, Óscar. ¿Qué es la teatralidad? Paradigmas estéticos de la Modernidad. Agenda Cultura. N 158. 2009. Essas idéias são apontadas nesse texto, porém no último aspecto sobre a teatralidade faço algumas inserções provindas da minha reflexão a parir dessa leitura. 
O conceito de "teatro teatral" elaborado por Meyerhold nos leva a pensar exatamente no olhar do outro como essencial para a constituição de uma teatralidade em que o artista se organiza para dizer algo e promover, no encontro com o espectador, a capacidade de permitilo ler o que está diante dele numa relação entre quem faz e quem vê. Considerando-se mais uma vez a questão do literal em contraposição à teatralidade, pensa-se no valor dado à palavra, para que esta não se torne única direcionadora na construção da teatralidade diante do olhar do púbico.

Mostaço (2010) afirma que existem duas formas de colocação da palavra: a primeira que direciona a imaginação do leitor ou do espectador e, assim, produz uma representação exata do que se está propondo, e uma segunda em que a palavra é usada como um ato de vontade, na qual o ator a expressa, permitindo que os espectadores a relacionem com o espaço, com o tempo e com os outros espectadores. Trata-se, portanto, também, do olhar de quem cria a partir de seu processo de percepção e afetação, não se detendo em um único e possível significado, pois a teatralidade é um “dado da criação, não de realização" ${ }^{6} \mathrm{e}$, assim sendo, ela começa a ser construída nos momentos em que ainda se experiencia o processo criativo.

O segundo ponto de discussão acerca das características que implicam a teatralidade refere-se à efemeridade do aqui/agora, de como o atuante apropria-se dessa situação não prevista, mas sim instaurada. A teatralidade torna-se algo que não está pronto e acabado, mas em sobressaltos, pois se manifesta inteiramente a partir da relação com o espectador e também com os demais elementos do espaço e do tempo.

Nesse sentido, a teatralidade passa do momento da criação para a realização, sendo que os elementos do aqui/agora se mantêm aptos a constantes e intermináveis mudanças, na medida em que a realização estabelece formas de colocar atuantes e espectadores diante uns dos outros naqueles instantes.

Essa condição já estabelecida entre atuante e espectadores enfatiza a idéia do terceiro aspecto da teatralidade: a presença corporal, ao invés da lógica de um personagem. A presença mantém esse caráter de efemeridade do aqui/agora e pode ser preservada pela própria relação com o espaço/tempo que age e reage no e com o corpo do atuante inserido naquele determinado contexto. Trata-se de um estado de permanência naqueles instantes e o corpo responde ao interesse ${ }^{7}$ das relações. Este está vinculado aos interesses pessoais diante

\footnotetext{
${ }^{6}$ Idem, p.47.

${ }^{7}$ BOGART, Landau, 2005.
} 
das circunstâncias, e é primordial que ele seja mantido, pois o corpo não se disfarça, ou seja: não se trata do que um outro sente, pensa ou experiencia, mas são as próprias experiências que, mantidas pelo intrínseco interesse, geram essa presença.

A teatralidade, portanto, é pensada como um conceito que pode permear as práticas teatrais escolares na busca de evidenciar construções e leituras que têm como pressuposto principal a não literariedade. A partir disso, entende-se que essa teatralidade é construída pelo olhar do espectador diante dos atuantes que buscam no aqui/agora as possibilidades de relações mutáveis. O olhar e as relações criam nos atuantes uma presença consciente, que os permite dilatar suas experiências para esse contexto e/ou situação presente, a fím de que espectadores elaborem a teatralidade juntamente com ele.

Para se chegar à construção da teatralidade contemporânea, os viewpoints apresentam possibilidades que viabilizam o entendimento de conceitos aplicáveis, sobretudo também ao

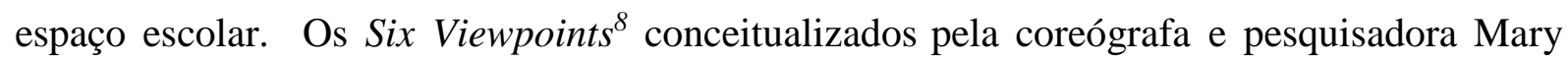
Overlie, tem a proposta de estudar o tempo e o espaço na improvisação em dança. A pesquisadora norte-americana Anne Bogart, em contato com os estudos de Mary Overlie, adota essa prática em seu trabalho de diretora, ampliando para nove os pontos de atenção: os viewpoints físicos (Relação Espacial, Resposta Sinestésica, Forma, Gesto, Repetição, Duração, Tempo, Arquitetura e Topografia) e seis viewpoints vocais (Altura, Dinâmica, Andamento, Aceleração/Desaceleração, Timbre e Silêncio).

A investigação dos viewpoints físicos por meio de exercícios propostos por Bogart e Landau em "The viewpoints book" e os jogos teatrais propostos por Viola Spolin em "Os jogos teatrais: o fichário de Viola Spolin" possibilitam que a investigação acerca das teatralidades contemporâneas se dê no espaço escolar, sem necessariamente, que um procedimento de ensino exclua o outro.

Pelo contrário, os viewpoints - por priorizarem o caráter improvisacional, no qual os indivíduos são levados a buscarem novas formas de relação com o tempo e com o espaço focalizam a criação a partir do entendimento de uma teatralidade diferente da que normalmente é absorvida e construída social e culturalmente no espaço escolar. Os jogos teatrais, mesmo que em muitos jogos Spolin proponha a estrutura dramática do onde, quem e o que, também trazem essa relação com a improvisação, a busca de uma sensibilização e percepção quanto ao jogo que é construído com o espaço e com o outro no "aqui" e no "agora". A junção desses procedimentos possibilita ampliar as referências quanto á criação no

\footnotetext{
${ }^{8}$ Os Seis Viewpoints: espaço, forma, tempo, emoção, movimento e história.
} 
teatro já que escola, por sua vez, reproduz tanto o gosto cultural midiático e televisivo das novelas quanto o processo cognitivo de apropriação da realidade por meio da imitação natural do ser humano, baseado no realismo ${ }^{9}$.

"A teatralidade realiza-se no cotidiano"10, de maneira espontânea e inerente, e está presente nos objetos, nos sons e nos corpos. Porém, é preciso incorporá-los enquanto potencializadores do ato criativo. Os conceitos dos viewpoints oportunizam que os alunos envolvidos nessas práticas ampliem suas relações com (no) espaço/ tempo, e construam uma teatralidade que pode ampliar suas referencias á medida em que vão durante a experiência entendendo e criando novas formas de relação com o que está posto cotidianamente. Assim, vai se tornando possível a construção de teatralidades que acentuem a não literariedade, mas a capacidade de instaurar a presença no aqui/agora, que dê ao espectador a possibilidade do olhar sobre o efêmero e que seja capaz de estabelecer o jogo, a relação entre quem faz e quem assiste.

O objetivo, segundo Soares (2010) é "desenvolver um olhar intencionado, o olhar consciente sobre as formas no espaço, ampliando a experiência sensível dos alunos (...)". Os viewpoints na escola enquanto conceitos que podem fundamentar a prática na escola já nos indicam a busca por esse olhar, que segundo Bogart (2005), é chamado de soft focus (foco suave) e que se estende ao corpo por meio também de uma escuta extraordinária.

O soft focus (foco suave) está vinculado ao desenvolvimento de uma visão em que os olhos são capazes de perceber não mais somente eventos isoladamente, mas inúmeros e simultâneos acontecimentos em seu entorno, sem manter um foco único e direcionado. Dessa forma, permite-se que as informações cheguem até os olhos, mas passando por todas as outras partes do corpo, por meio da sensibilização dos outros sentidos.

Quando isso acontece, o indivíduo vai se tornando apto a ter uma escuta extraordinária, ou seja, depois de aprender a ver com todos os sentidos, ele também aprende a ouvir com todas as partes do corpo, estando sempre em prontidão diante do que o circunda. Essa escuta não é premeditada e não busca resultados previsíveis. "A certeza não nos estimula emocionalmente" ${ }^{\prime 1}$, por isso, a escuta está aberta para si e para o outro. O indivíduo está pronto para ter uma resposta diante dos eventos que o impulsionam à ação e ao movimento de

\footnotetext{
${ }^{9}$ ANDRÉ, C. (2007): Essa idéia é trazida para o Brasil pela pedagoga Joana Lopes que cita o realismo como uma das fases de desenvolvimento da criança. P. 103/104.

${ }^{10}$ SOARES, 2010, p. 77.

${ }^{11}$ BOGART, 2009, p. 33.
} 
maneira consciente diante de tudo e de todos, posto que ele mesmo está diante dos espectadores experenciando aquelas possibilidades.

O trabalho para o desenvolvimento desse olhar que também é escuta, torna possível que o entendimento se dê unicamente pelo fazer, pois não se ensina a olhar e a escutar, somente criam-se condições para que olhos e ouvidos estejam aptos a lidarem com outras formas de se relacionar teatralmente com os outros e com o mundo. Se as teatralidades contemporâneas já pertencem a esse ambiente escolar por meio da relação que os próprios alunos estabelecem com a sociedade, é com a inserção de professores que se utilizam de suas práticas artísticas nos ambientes educacionais favorecerá sempre a permutação de teatralidades nesse espaço.

Como tornar, portanto, a teatralidade algo cotidiano no ambiente escolar? Como utilizar do cotidiano para a investigação acerca dos aspectos presentes nas teatralidades contemporâneas? (relações não-convencionais de ocupação do espaço-principalmente em contraposição ao palco italiano, por ser uma referência constante para os alunos-; construção da teatralidade que se realiza pela relação que se estabelece com o espectador; a idéia de uma presença corporal instaurada na efemeridade do aqui/agora que é apresentada não pela lógica de um personagem, mas a partir da presença motivada pelo interesse).

O olhar do professor também precisa ser soft focus (foco suave), ou seja, perceber ao seu redor quais as proposições desse espaço escolar e em que medida isso vai sendo reapropriado para a linguagem da teatralidade. Esse olhar atento pode apontar caminhos a serem percorridos ao longo de um processo de criação, cujas perspectivas visem justamente, uma construção que inclua também as necessidades e particularidades do grupo envolvido.

$\mathrm{O}$ que torna uma história/fato uma memória presente em nossas vidas? O afeto, as sensações, os sentimentos, as necessidades sociais, a relação entre memória individual e coletiva e as experiências do presente podem ser apontadas como modos de vincular a memória a processos que são rememorativos. As sensações, os afetos, as percepções e os sentimentos são de caráter mais subjetivo do sujeito, ou seja, são pertencentes à individualidade de cada um, por isso, mesmo que pessoas diferentes tenham vivenciado os mesmos fatos e/ou histórias, cada uma pode trazer um tipo de envolvimento afetivo com aquilo e, por isso, ao serem estimulados pelo presente são capazes de fazer "emergir atualizando aquilo que não existe mais há muito tempo.” 12

${ }^{12}$ SEIXAS apud LEAL (2011) 
As questões sociais presentes nos estudos de Halbwachs estão totalmente fundamentadas na organização da memória que é individual e coletiva. O autor, segundo Leal (2011), não enfatiza as questões subjetivas, como sensações e os sentimentos, porque para ele a memória "é a reconstrução do passado a partir dos quadros sociais presente", ou seja, são as relações estabelecidas com a sociedade que pautam a construção de uma memória coletiva, e a memória individual torna-se um fragmento sobre a totalidade do coletivo. Portanto, são também as experiências do presente que impulsionam a busca por determinado tipo de memória, permitindo que o sujeito eleja determinado fato/ história de sua vida de acordo com o tipo de relação que a própria experiência está lhe impondo.

O uso da memória levanta fatos que são abordados ora de maneira individual (particular de cada aluno) e ora coletiva (porque perpassam pela relação dos pais com aquele fato), mas que reaparecem pela necessidade da experiência proposta no presente. Cada processo criativo solicita que a memória acione determinados fatos/historias, de modo a contemplar as investigações que estão sendo feitas. Portanto, é fato que para cada tipo de processo criativo um tipo de memória vai ser acionado, suscitando diferentes experiências a partir de vivências já ocorridas.

Há sempre nos processos de criação uma ressignificação das próprias percepções, sensações, afetos e sentimentos dos alunos/ atuantes na medida em que se experimentam aquela memória. Primeiramente porque isso implica em compartilhar de algo que, a princípio é individual, mas que passa a ser coletivizado. Em segundo lugar, o procedimento que vai sendo adotado para se chegar a uma estética teatral, impulsiona o entendimento da memória pela via da criação de uma estética teatral. No caso, dos viewpoints serem o norte conceitual e prático, os alunos/atuantes são colocados em situações que exigem uma escuta extraordinária para que possam reorganizar os elementos que eram, a princípio, somente vinculados à memória, mas que precisavam também abarcar os conceitos, outras formas de relação com espaço/tempo na reconstrução da memória.

Essas proposições em relação à memória implicam um percurso em "via de mão dupla" para o aluno/atuante. Ao passo que suas percepções, sensações e sentimentos em relação à memória eram alterados, porque estão agora inseridos em outra experiência, que não é mais o momento já vivido, existe uma afetação dos seus sentimentos pela experiência no presente. Assim, as relações com a memória dialogam com os conceitos apontados pelo encenador Stanislavski. ${ }^{13}$ Para este autor, ideias e ações demonstram que sentimentos e afetos

${ }^{13}$ STANISLAVSKI apud LEAL (2011)

Rascunhos Uberlândia v. 1 n. 2 p. 63-77 jul.|dez. 2014 
implicam em uma "memória das emoções ou afetivas" e que percepções e sensações são provenientes de uma "memória sensorial". Ambas as memórias interfeririam na experiência do ator e o ator também reconstruiria a experiência a partir de suas memórias.

O papel da memória das "emoções ou afetiva" seria o resgate de uma emoção já vivida pelo ator para preencher os sentimentos na construção de um personagem. Já a memória sensorial é “(...) a coisa capaz de sugerir essa sensação, ou seja, de fazê-la renascer, fraca, primeiro, mas forte em seguida, cada vez mais à medida que a atenção se fixa mais nela"14. Por meio da sensação, o ator aciona sua imaginação e a projeta em suas ações.

Quando Viola Spolin propõe a fisicalização de um “onde", um "quem” e um "o que" por meio dos jogos teatrais, o que está se solicitando aos jogadores é exatamente uma relação com a sensorialidade, na qual o objetivo não é a pantomima, mas sim a exteriorização do que está invisível. O importante é mostrar em ações a subjetividade das sensações a partir de determinada situação.

Esses dois tipos de memória podem ser usados nos processos criativos simultaneamente, não necessitando de separações estanques, pois ambos podem ocorrer e serem trabalhados para não acontecerem um em detrimento do outro. Pensando ainda em uma relação em que tais memórias sejam parte de um procedimento que visa o ensino/aprendizagem a partir de teatralidades contemporâneas, elas podem ser usadas como mais um conceito a ser explorado na relação espaço/tempo.

Nesse caso, a memória tem a capacidade de fazer o aluno/atuante resgatar suas memórias afetivas ou sensoriais que pertencem a um passado, mas que ao serem transposta para o aqui/agora são re-elaboradas por outras possíveis relações. A memória, então, está sujeita às constantes mudanças, pois se coloca no tempo transitando entre o passado e o presente e no espaço entre o eu e o outro. Dessa forma, o atuante pode conseguir o ir e o vir do interior para o exterior e vice-versa, justamente porque, como acreditava Stanislavski, tudo que está no ator pertence ao seu material criativo e, portanto, é ele capaz de acionar quaisquer meios que o coloquem em estado de presença em cena, inclusive a memória que "poderá ser incluída visando um maior aprofundamento do tema a ser trabalhado". ${ }^{15}$

Stanislavski, segundo Leal (2011), não define o que um ator precisa seguir para alcançar a memória e assim para ter mais um subsídio - seja por estímulos interiores ou exteriores- que não torne a cena vazia pela ausência do estado de presença. Os próprios

\footnotetext{
${ }^{14}$ BERGSON apud LEAL (2011)
}

${ }^{15}$ LEAL, 2011, p. 62 
viewpoints quando trabalham com o conceito de repetição, instigam o uso da memória pelo exercício da ação física (estímulo exterior) que, como também acreditava Stanislavski, seria capaz de se tornar repetível para que houvesse a criação.

$\mathrm{O}$ atuante, quando usa repetição como um dos conceitos presentes nos viewpoints, apropria-se das relações que o outro estabelece no espaço/tempo, expressando-as por meio de suas ações físicas. Quando a memória capta o instante do estímulo externo, o atuante torna-se capaz de repeti-lo impregnando-o de seus sentimentos, seus afetos, suas sensações e suas emoções, que podem acionar outras memórias que são afetivas ou sensoriais. Isto é: trata-se da memória do estímulo externo do aqui/agora alimentando o acesso às "memórias das emoções e das sensações". Mas toda ação física traz à tona algum tipo de memória?

Creio que sim. Algumas são memórias apresentadas na forma de lembranças (imagens) que denotam a "memória das sensações" e outras podem ser sentimentos resgatados pela "memória das emoções". Nos viewpoints toda ação será executada porque algo mobiliza o atuante a agir de tal forma, a ação é sempre mobilizada por algo externo a esse atuante, mas isso não implica que impulsos internos (como as memórias das emoções e das sensações) também sejam ativados.

\section{MEMÓRIA $\Longrightarrow$ AÇÃO $\longleftrightarrow$ RESSIGNIFICAÇÃO DA MEMÓRIA}

Os alunos/atuantes quando acionam histórias/fatos (memórias individuais e/ou coletivas), e são estimulados a experenciarem essa memória pelo uso dos conceitos dos viewpoints, elas reaparecem como ações físicas. Essas ações em relação com o espaço (arquitetura, topografia, gesto, forma, relação espacial entre as pessoas envolvidas) e com o tempo (duração, repetição, tempo e resposta sinestésica) ganhavam um significado diferente daquele que estava presente na memória inicial das histórias/fatos. Consecutivamente, a ação inicial também se modifica na medida em que outros elementos do aqui/agora (tanto os conceitos dos viewpoints, como inserção de outros elementos levados pelo professor propositor, como objetos e músicas) vão sendo acrescentados.

As memórias aproximam os atuantes de seus próprios contextos (passado e presente). E num processo de afetação, memórias são re-significadas pelas novas experiências e as experiências atuais passam a ser re-elaboradas pelas memórias. A memória, então, passa a fazer parte do processo de criação que é um fazer pedagógico e artístico. As histórias/fatos levantadas colocam os alunos/atuantes em apropriação de um material que advém da individualidade, assim, eles são co-autores de um processo que parte essencialmente daquilo que cada um pode e quer colocar em cena. Mas o fazer artístico implica em recriar, em trans- 
formar e reelaborar os entendimentos e as pessoalidades para que esse fazer alcance a teatralidade que dali pode emergir.

Referências

AGAMBEN, Giorgio. O que é o contemporâneo? E outros ensaios. Tradução Vinícius Nicastro Honesko. Chapéco: Argos, 2009.

ANDRÉ, Carminda Mendes. O teatro pós-dramático na escola. Tese (Doutorado em Educação). Faculdade de Educação da Universidade de São Paulo. São Paulo. 2007.

BOGART, Anne. Seis coisas que sei sobre o treinamento de atores. Urdimento, v.1, n.12, p.29-40.2009

BOGART, Anne. LANDAU, Tina. The Viewpoints Book. A practical Guide to Viewpoints and Composition. New York: Theatre Communications Group, 2005.

CABRAL, Biange. O professor-artista: perspectivas teóricas e deslocamentos históricos. Urdimento, vol.01, n 10, p. 35-44. 2008.

CONARGO, Óscar. ¿Qué es la teatralidad? Paradigmas estéticos de la Modernidad. Agenda Cultura. N 158. 2009.

DEBORTOLI, Camila Rodrigues. Professor e artista ou professor-artista? DAPesquisa, n.08, ago. 2010 a jul.2011.

FABIÃO, Eleonora. Performance, Teatro e Ensino. In: TELLES, Narciso, FLORENTINO, Adilson (orgs). Cartografias do Ensino do Teatro. Uberlândia: EDUFU, 2009. P. 61-72.

FÉRAL, Josette. Teatro performativo e pedagogia. Entrevista. Sala Preta, v.1, n.09, p. 255268, dez.2009.

LEAL, Mara Lucia. Performance e[m] memória: material autobiográfico na composição da cena. Tese (Doutorado em Artes Cênicas). Programa de Pós-Graduação em Artes Cênicas da Universidade Federal da Bahia. Salvador. 2011.

MOSTAÇO, Edelcio. Teatralidade, a espessura do olhar. In: (org). Para uma história cultural do teatro. Florianópolis: Design Editora, 2010.

PUPO, Maria Lucia Barros. Além das Dicotomias. Anais do Seminário Nacional de Arte e Educação. Montenegro, RS: Fundação Municipal de Artes de Montenegro, pp. 31-34, 2001.

SOARES, Carmela. Pedagogia do jogo teatral: uma poética do efêmero. São Paulo: Hucitec, 2010. 